\title{
CLOSURE OF THE CYSTIC DUCT DURING LAPAROSCOPIC CHOLECYSTECTOMY BY THE LIGASURE VESSEL SEALING SYSTEM
}

\author{
By \\ AYMAN NAFEA ${ }^{1}$, HESHAM ABDELAZIZ ${ }^{*}$, HASSAN SHAKER ${ }^{2}$, MAGED NASR ${ }^{1}$, \\ ASAAD FAYROUZ ${ }^{1}$, HOSAM HAMDY ${ }^{1}$ and MAHMOUD RADY ${ }^{1}$
}

Department of General Surgery, Theodor Bilhariz Research Institute ${ }^{1}$, Imbaba P. O. Box 30 Giza, and Department of General Surgery, Faculty of Medicine, Ain Shams University ${ }^{2}$, Cairo 11566, Egypt ( ${ }^{*}$ Correspondence: hesham1983@hotmail.com)

\section{Abstract}

Laparoscopic cholecystectomy is the "gold standard" in the treatment of symptomatic gallbladder lithiasis. Nevertheless, some pitfalls are associated with the use of the monopolar hook, such as the risk of thermal injuries and biliary complications. The present study assessed the efficacy of the LigaSure Vessel Sealing System (LVSS) when used for cystic duct closure during laparoscopic cholecystectomy.

The laparoscopic cholecystectomy was done beginning with visualization of Calot's triangle, and dissection of Calot's triangle was achieved using a monopolar cautery device. Once the cystic duct was exposed, sealing was performed and divided using the LVSS. The records were compared with those of patients undergoing laparoscopic cholecystectomy with closure of the cystic duct with clips during the same period.

The results showed that during the study period, 218 laparoscopic cholecystectomies were performed; 82 of these were performed with the Liga-Sure. The work was experienced a single case of bile leakage from the cystic duct due to missed stone in the common bile duct that was managed using ERCP.

Key Words: Cholecystectomy, Gall bladder, Complications, Cystic duct leakage, Liga-Sure, LVSS.

\section{Introduction}

Initially, the LigaSure vessel sealing system (LVSS) was intended for sealing vessels up to $7 \mathrm{~mm}$ in breadth as another option to the utilization of clips or ligature (Yao et al, 2009). Relative ponders have been demonstrated that it is as protected, attainable, and indeed, even valuable as other vessel closure procedures, for example, the plasma trisector, Ultracision, surgical clip application, symphonious surgical tool, and customary hemostasis (Cakabay et al, 2009).

In late years, there has been an expanding number of reports on the utilization of the LVSS not just for sealing vessels yet additionally for the dismemberment/transection of different delicate and parenchymatous tissues (Nouri et al, 2009). In liver resection, pancreatectomy, pneumonic resections, hysterectomy, LigaSure-assisted laparoscopic appendectomy, also, even hemorrhoidectomy (Kova'cs et al, 2009; Aydogan et al, 2009; Sucullu et al, 2009; Lambert et al, 2010; Elemen L, et al, 2010; Hartwig et al, 2010; Cakan et al, 2010).
Additionally, the utilization of the LVSS for the transection of major Glisson bundles and major bile ducts, also for the closure of the cystic duct during cholecystectomy, has been accounted for in animal display trials and in the ex vivo setting (Matthews et al, 2001; Shamiyeh, et al, 2002; Schulze et al, 2002; Shamiyeh et al, 2004; Nii et al, 2008; Fong et al, 2018). The closure of the cystic duct during laparoscopic cholecystectomy was utilizied the LVSS system.

The present study aimed to evaluate the efficacy of the Liga-Sure Vessel Sealing System (LVSS) for cystic duct closure during laparoscopic cholecystectomy of patients.

\section{Materials and Methods}

This study dealt with 82 patients of both sexes from Theodor Bilhariz Research Institute Hospital scheduled for elective laparoscopic cholecystectomies were consecutively included in the study. The results were compared with those of a control group of 136 patients undergoing elective laparoscopic cholecystectomy with a normal closure of the cystic duct with titanium clips during the 
same period in the same department. The patients in the control group were operated on in the stationary ward. The surgery in both groups was performed by the same team of surgeons. The $10-\mathrm{mm} \& 5-\mathrm{mm} \mathrm{Li}-$ ga-Sure ForceTriad system (Valleylab, Boulder, Colorado, USA) were applied perpendicularly to cystic duct at least $3 \mathrm{~mm}$ from the common bile duct, and the duct was measured using the device blade (Figs. 1 \& 2 ), sealed with sufficient energy and divided with the instrument knife (Figs. $3 \& 4$ ).

The cystic duct was closed with 3 clips in the control group, 2 of these were applied below where it was transsected. Patients with a cystic duct wider than $1 \mathrm{~cm}$ or shorter than $1 \mathrm{~cm}$, or both were excluded from the study. The dimensions of the cystic duct were measured using the tip of the LigaSure. As the bile duct is a low-pressure system compared with the arterial system, we decided to include patients with the mentioned dimensions in the study, although the system according to the literature only supports sealing of vessels up to $7 \mathrm{~mm}$.

A concept statement was obtained from each patient after clarifying the study design. The study was approved by the local Ethics Committee and conducted in accordance to the Helsinki II Declaration (World Medical Association, 2013).

Statistical analysis: A comparison between qualitative variables was made using the $\mathrm{X} 2$ test or Fisher's exact test where appropriate, while the student $t$ test was chosen for nonnormally and normally distributed variables, respectively. $\quad \mathrm{P}<0.05$ was significant (McDonald, 2001).

\section{Results}

During the study period, March 4, 2016 through April 5, 2017, two hundred and eighteen patients were enrolled in this study.
They were divided into two groups: group A (82 patients) underwent Laparoscopic Cholecystectomy with LigaSure Sealing System, and group B (136 patients) underwent laparoscopic cholecystectomy with titanium clip control group. Both groups were similar in age, sex, and BMI (Tab. 1). Furthermore, both groups were similar in the presenting symptoms and number of stones (Tab. 2).

The mean time for closure of the cystic duct, conversion rates, postoperative hospital stay, CD length, CD diameter and morbidity for each group were analyzed and compared with each other (Tab. 3). Laparoscopic cholecystectomy was successfully completed in 216 patients (99\%). Conversion was necessary in 2 patients $(0.91 \%)$ in group B due to diffuse peritoneal adhesions. Intraoperative cholangiography was performed in 10 cases ( 2 in group A and 6 in group B). The median time for closure of the cystic duct was $0.92 \pm 0.54$ in group A vs. $2.42 \pm 1.85$ min in group $B$ with significant difference $\mathrm{P}=0.031$

The mean postoperative hospital stay, pain score, analgesia score and postoperative complications were analyzed and compared with each other of all patients without significant difference between groups (Tab. 4).

In this study, a single case of cystic duct leakage in the study group. The patient developed pain the day after surgery, and a collection was noticed in the operative bed. ERCP was done and showed missed stone in the common bile duct and bile leakage from the cystic duct (Fig. 5), the stone was removed and a stent was inserted. A pig tail was inserted in the site of the collection. This patient recovered and was discharged after 4 days. The stent was removed after 3 months without complications.

Table 1: Demographic data of patients and control.

\begin{tabular}{|c|c|c|c|c|}
\hline Variables & \multicolumn{2}{|c|}{ Control group $(\mathrm{N}=136)$} & Study group $(\mathrm{N}=82)$ & P value \\
\hline Age $($ Mean $+\mathrm{SD})$ & \multicolumn{2}{|c|}{$36.20 \pm 2.389$} & $43.00 \pm 2.910$ & 0.0788 \\
\hline \multirow{2}{*}{ Sex } & Male & $22(16 \%)$ & $11(13 \%)$ & \multirow{2}{*}{0.374} \\
\cline { 2 - 5 } & Female & $114(84 \%)$ & $71(87 \%)$ & \\
\hline \multicolumn{2}{|c|}{ BMI (Mean +SD) } & $33.8 \pm 6.41$ & $33.6 \pm 4.34$ & 0.9110 \\
\hline
\end{tabular}


Table2: Laparoscopic cholecystectomy (LigaSure sealing system) in patients compared to titanium clip controls

\begin{tabular}{|c|c|c|c|c|}
\hline \multicolumn{2}{|c|}{ Variables } & Control group $(\mathrm{N}=136)$ & Study group (N=82) & P value \\
\hline \multirow{2}{*}{ Symptom } & Pain in Rt. hypochondrium & $98(72 \%)$ & $70(85 \%)$ & \multirow{2}{*}{0.4506} \\
\cline { 2 - 5 } & Fatty dyspepsia & $38(28 \%)$ & $12(15 \%)$ & 0.526 \\
\hline \multicolumn{2}{|c|}{ History of biliary colics } & $111(82 \%)$ & $54(65 \%)$ & 0.374 \\
\hline \multicolumn{2}{|c|}{ History of acute attack } & $22(16 \%)$ & $9(11 \%)$ & -- \\
\hline \multicolumn{2}{|c|}{ History of obstructive jaundice } & 0.0 & 0.0 & \multirow{2}{*}{0.9110} \\
\hline \multirow{2}{*}{ Number of stones } & Single & $33(24 \%)$ & $64(78 \%)$ & \\
\cline { 2 - 5 } & Multiple & $103(76 \%)$ & $6.90)$ & \\
\hline
\end{tabular}

Table 3: Laparoscopic cholecystecomy (LigaSure sealing system) patients compared to titanium clip controls.

\begin{tabular}{|c|c|c|c|}
\hline Variables & Control group $(\mathrm{N}=136)$ & Patients group $(\mathrm{N}=82)$ & P value \\
\hline $\begin{array}{c}\text { Mean operative time needed for } \\
\text { closure of the cystic duct } \pm S D\end{array}$ & $2.425 \pm 1.854 \mathrm{~min}$ & $0.925 \pm 0.54 \mathrm{~min}$ & 0.031 \\
\hline Conversion rate & 2 cases & 0.0 & 0.528 \\
\hline Mean CD length \pm SD & $2.200 \pm 0.1328 \mathrm{~cm}$ & $2.450 \pm 0.1491 \mathrm{~cm}$ & 0.218 \\
\hline Mean CD width \pm SD & $0.725 \pm 0.0228 \mathrm{~cm}$ & $0.665 \pm 0.0264 \mathrm{~cm}$ & 0.093 \\
\hline Intraoperative cholangiography & 6 cases & 2 cases & 0.7131 \\
\hline Mean intraoperative blood loss & $9.250 \pm 5.121$ & $1.750 \pm 1.105$ & 0.1604 \\
\hline
\end{tabular}

Table \$: Laparoscopic cholecystecomy (LigaSure sealing system) patients compared to titanium clip controls (postoperative variables)

\begin{tabular}{|c|c|c|c|c|}
\hline \multicolumn{2}{|c|}{ Variables } & Control group $(\mathrm{N}=136)$ & Patients group $(\mathrm{N}=82)$ & $P$ value \\
\hline \multirow{3}{*}{$\begin{array}{l}\text { Pain } \\
\text { score }\end{array}$} & First day & 8 & 7.59 & \multirow{3}{*}{0.9804} \\
\hline & Second day & 6.65 & 6.35 & \\
\hline & Third day & 5.85 & 5.4 & \\
\hline \multirow{3}{*}{$\begin{array}{c}\text { Analgesia } \\
\text { score }\end{array}$} & First day & 3.5 & 3.5 & \multirow{3}{*}{0.8813} \\
\hline & Second day & 3.2 & 2.9 & \\
\hline & Third day & 2.35 & 1.85 & \\
\hline \multicolumn{2}{|c|}{ Bleeding } & 0.0 & 0.0 & \\
\hline \multicolumn{2}{|c|}{ Bile leakage } & 0.0 & $1(5 \%)$ & 0.9998 \\
\hline \multicolumn{2}{|c|}{ Jaundice } & 0.0 & 0.0 & \\
\hline \multicolumn{2}{|c|}{ Hospital stay } & $2.200 \pm 0.1170$ & $1.350 \pm 0.254$ & 0.5950 \\
\hline \multicolumn{2}{|c|}{ Wound infection } & 5 & 3 & 0.6948 \\
\hline
\end{tabular}

\section{Discussion}

Generally speaking, Cholecystectomy is indicated in the presence of gallbladder trauma, gallbladder cancer, acute cholecystitis, and other complications of gallstones. More controversial are the indications for elective cholecystectomy (Potts, 1990). Epidemiological studies showed gall bladder carcinoma to be the $6^{\text {th }}$ common cancer involving gastrointestinal system (Goodman and Wagman, 2010). Also, many parasites encounterred in Egypt cause acute cholecystitis, as malignant malaria (Abreu et al, 2013) ascariasis (Azhar et al, 2015), toxocariasis (Strickler et al, 2016) and giardiasis (Araki et al, 2017) as well as Staphylococcus saprophyticus, Corynebacterium urinapleomorphum, and Heliobacter pylori (Backert et al, 2018).

The principal finding in the study was that the 5-mm and the 10-mm LigaSure ForceTriad system provided sufficient sealing of the cystic duct and the cystic artery in patients undergoing laparoscopic cholecystectomy. The 5-mm laparoscopic LigaSure system has been shown to be effective in liver surgery when transection of the liver is performed, including division of the small bile ducts (Saiura et al, 2008; Slakey 2008).

The LigaSure system proved to be effective for blood vessel sealing in many studies comparing it with monopolar electrocoagulation, bipolar coagulation, or ultrasonic techniques (Diamantis et al, 2006; Newcomb et al, 2009; Singal et al, 2018). However the LigaSure system has no previously been reported for sealing of the cystic duct in human studies, but in an animal study we found the method to be safe. This has re- 
cently been confirmed by closure of the major bile ducts in pigs (Nii et al, 2008).

One potential advantage of the LigaSure is that it leaves no metallic objects in the body and that the risk of damage of the surrounding structures is minimal due to the bipolar cautery. However, the cost of the instrument is higher than the cost of the clip applier. The present results with a single case of leakage suggest that the use of the new 5$\mathrm{mm}$ LigaSure is safe and may be used for division of a cystic duct in patients undergoing laparoscopic cholecystectomy.

\section{Conclusion}

Generally speaking, there are so many microbiol and parasitic diseases condition indicating the laparoscopic cholecystectomy.

The LigaSure Vessel Sealing System (LVSS) is not only a safe and effective instrument but also a reliable substitute for clips because it provides complete hemobiliary stasis. Even if the study revealed no differences with regard to postoperative complications, the LVSS represents a viable alternative because of the shorter operation time and cost savings that are inherent in a procedure using it as a single instrument. The instrument proved to be suitable for dissection, sealing, and division of the cystic duct and the tissue anchoring the gallbladder to the gallbladder bed in the liver. Whether this might lead to shortening of operation time and a reduction of the total cost needs to be elucidated.

Conflict of Interest: The authors declare that they neither have conflict of interest nor received funds

\section{References}

Abreu, C, Santos, L, Poínhos, R, Sarmento, A, 2013: Acute acalculous cholecystitis in malaria: A review of seven cases from an adult cohort. Infection 41, 4:821-6

Araki, H, Shimizu, S, Hayashi, K, Yamada, T, Kusakabe, A, et al, 2017: Acute acalculous cholecystitis caused by Giardia lamblia. Intern. Med. 56, 13:1657-62

Aydogan, F, Saribeyoglu, K, Simsek, O, et al, 2009: Comparison of electrothermal vessel-seal- ing system versus endoclip in laparoscopic appendectomy. J. Laparoendosc. Adv. Surg. Tech. 19, 3:375-8.

Azhar, M, Sheikh, AS, Khan, A, Mustafa, S, Shah, IA, et al, 2015: Hepatobiliary ascariasis complicated by pancreatitis. J. Ayub Med. Coll. Abbottabad. 27, 2:479-81

Backert, S, Tegtmeyer, N, Oyarzabal, OA, Osman, D, Rohde, M, et al, 2018: Unusual manifestation of live Staphylococcus saprophyticus, Corynebacterium urinapleomorphum, and Heliobacter pylori in the gallbladder with Cholecystitis. Int. J. Mol. Sci. 19, 7. pii: E1826.

Cakabay, B, Sevinc, MM, Go"mceli, I et al, 2009: LigaSure versus clamp-and-tie in thyroidectomy: a single-center experience. Adv. Ther. 26, 11:1035-41.

Cakan, A, Yoldas, B, Samancilar, O, et al, 2009: LigaSure vessel sealing system versus harmonic scalpel for sutureless nonanatomical pulmonary resections in a rabbit model: Which one is safer? Eur. Surg. Res. 43, 1:24-8.

Diamantis, T, Kontos, M, Arvelakis, A, et al, 2006: Comparison of monopolar electrocoagulation, bipolar electrocoagulation: Ultra-cision, and ligasure. Surg. Today. 36:908-13.

Elemen, L, Yazir, Y, Tugay, M, et al, 2010: LigaSure compared with ligatures and endoclips in experimental appendectomy: How safe is it? Pediatr. Surg. Int. 26, 5:539-45.

Fong, ZV, Pitt, HA, Strasberg, SM, Loehrer, AP, Sicklick, JK, et al, 2018: California cholecystectomy group: Diminished survival in patients with bile leak and ductal injury; management strategy and outcomes. J. Am. Coll. Surg. 226: 568-76.

Goodman, KR, Wagman, AYH, 2010: Cancer of the liver, bile duct, and gall bladder. In: Leibel \& Phillips Textbook of Radiation Oncology. $3^{\text {rd }}$ ed., RT, Hoppe, TL, Phillips, M, Roach (eds), Elsevier, Saunders, Philadelphia.

Hartwig, W, Duckheim, M, Strobel, O, et al, 2010: LigaSure for pancreatic sealing during distal pancreatectomy. Wld. J. Surg. 34, 5:106670 .

Kova'cs, O, Sza'nto, Z, Krasznai, G, et al, 2009: Comparing bipolar electrothermal device and endostapler in endoscopic lung wedge resection. Interact. Cardiovasc. Thorac. Surg. 9, 1:114

Lambert, EH, Schachter, LR, Altamar, HO, et al, 2010: A sealed bladder cuff technique dur- 
ing laparoscopic nephroureterectomy utilizing LigaSure electrosurgical device: laboratory and clinical experience. J. Endourol. 24, 3:327-32

Matthews, BD, Pratt, BL, Backus, CL, et al, 2001: Effectiveness of the ultrasonic coagulating shears, LigaSure vessel sealer, and surgical clip application in biliary surgery: A comparative analysis. Am. Surg. 67, 9:901-6.

McDonald AM, 2001: Choosing reliable statistical software. PS: Political Sci. Polit. 34, 3: 681-7.

Newcomb, WL, Hope, WW, Schmelzer, TM, et al, 2009: Comparison of blood vessel sealing among new electrosurgical and ultra-sonic devices. Surg. Endosc. 23:90-6.

Nii, A, Shimada, M, Ikegami, T, et al, 2008: Efficacy of vessel sealing system for major Glisson bundles and major bile ducts. J. Hepatobil. Pancreat. Surg. 15, 5:522-7.

Nouri, K, Ott, J, Demmel, M et al, 2009: Bipolar vessel sealing increases operative safety in laparoscopic-assisted vaginal hysterectomy. Arch. Gynecol. Obstet. [Epub ahead of print].

Potts, JR, $3^{\text {rd }}$, 1990: What are the indications for cholecystectomy? leve Clin. J. Med. 57, 1:40-7

Saiura, A, Yamamoto, J, Koga, R, Seki, M, Yamaguchi, T, 2008: Liver transection using the LigaSure Sealing system. HPB (Oxford). 10: 239-43.

Schulze, S, Krisitiansen, VB, Fischer, HB, et al, 2002: Sealing of cystic duct with bipolar electrocoagulation. Surg. Endosc. 16, 2:342-4.

Shamiyeh, A, Schrenk, P, Tulipan, L, et al, 2002: A new bipolar feedback-controlled sealing system for closure of the cystic duct and artery. Surg. Endosc. 16, 5:812-3.

Shamiyeh, A, Vattay, P, Tulipan, L, et al, 2004: Closure of the cystic duct during laparoscopic cholecystectomy with a new feedbackcontrolled bipolar sealing system in case of biliary obstruction - an experimental study in pigs. Hepatogastroenterology 51, 58:931-3

Singal, R, Sharma, A, Zaman, M, 2018: The safety and efficacy of clipless versus conventional laparoscopic cholecystectomy: Our experience in an Indian Rural Center. Maedica (Buchar). 13:34-43.

Slakey, DP, 2008: Laparoscopic liver resection using a bipolar vessel-sealing device: LigaSure. HPB (Oxford). 10:253-5.

Strickler, A, Vásquez, N, Maggi, L, Hernández, J, Hidalgo, X, 2016: Toxocarosis and acalculous acute cholecystitis: Consequence or coincidence? Rev. Chilena Infectol. 33, 3:346-51

Sucullu, I, Filiz, AI, Kurt, Y. et al, 2009: The effects of LigaSure on the laparoscopic management of acute appendicitis: LigaSure assisted laparoscopic appendectomy. Surg. Laparosc. Endosc. Percutan. Tech. 19, 4:333-5.

World Medical Association, 2013: Declaration of Helsinki: Ethical Principles for Medical Research Involving Human Subjects. JAMA 310, 20:2191-4.

Yao, HS, Wang, Q, Wang, WJ, et al, 2009: Prospective clinical trials of thyroidectomy with LigaSure versus conventional vessel ligation: a systematic review and meta-analysis. Arch. Surg. 144, 12:1167-74.

\section{Explanation of figures}

Fig 1: Measurement of cystic duct size using LigaSure $5 \mathrm{~mm}$; dimensions (5 $\mathrm{mm} \times 18 \mathrm{~mm})$.

Fig 2: Measurement of t cystic duct size using LigaSure $10 \mathrm{~mm}$; dimensions $(10 \mathrm{~mm} \times 20 \mathrm{~mm})$.

Fig 3: Closure of t cystic duct using LigaSure 10-mm.

Fig 4: Closure of cystic duct using LigaSure 5-mm.

Fig 5: ERCP showing missed stone in CBD and Cystic. 


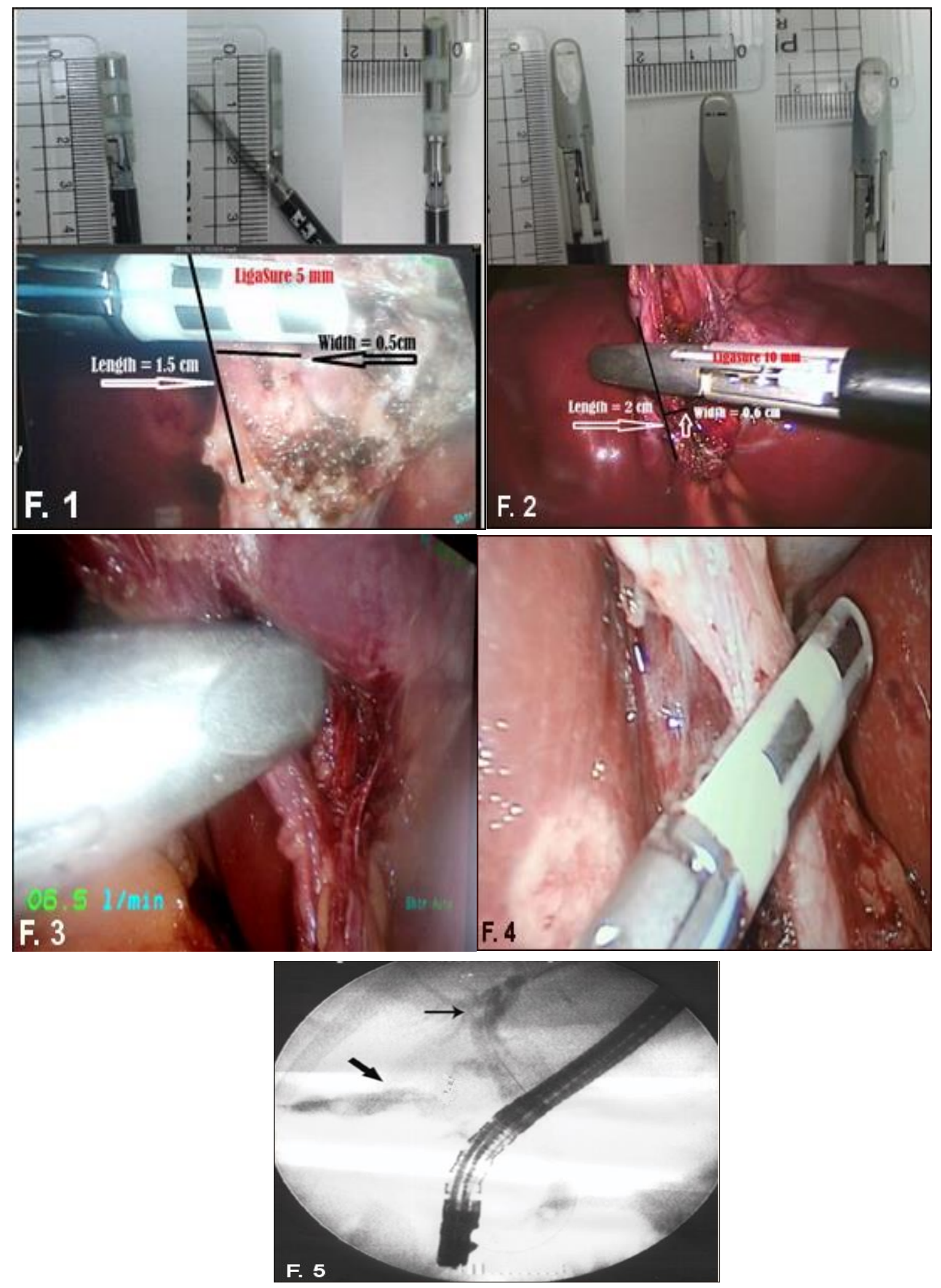

